\title{
La nación, la escuela y "los otros": reflexiones sobre la historia de la educación en Argentina y Colombia en el imaginario civilizatorio moderno
}

\author{
THE NATION, THE SCHOOL AND "THE OTHERS": THOUGHTS ABOUT THE HISTORY \\ OF EDUCATION IN ARGENTINA AND COLOMBIA IN THE MODERN CIVILIZATIONAL \\ IMAGINARY \\ A NAÇÃO, A ESCOLA E "OS OUTROS": REFLEXÕES SOBRE A HISTÓRIA DA EDUCAÇÃO \\ NA ARGENTINA E NA COLÔMBIA NO IMAGINÁRIO CIVILIZATÓRIO MODERNO
}

Anny Ocoró Loango*

Resumen

El presente artículo se centra en la historia de la educación en dos países latinoamericanos: Argentina y Colombia, para decodificar cómo, desde sus orígenes como nación, la intención de afianzar la nacionalidad y la ciudadanía se usó para la exclusión, la invisibilización o la integración subordinada de poblaciones y culturas que no eran consideradas parte de la nación. También señala las limitaciones que han tenido los análisis desde el campo de la historia de la educación en América Latina, para dar cuenta y problematizar el correlato racista y excluyente hacia los pueblos indígenas y las comunidades negras y afrodescendientes. Por último, ofrece una lectura sobre las líneas de investigación y aportes que diferentes autores vienen haciendo para analizar esta problemática desde los textos escolares.

\section{Abstract}

This paper focuses on the history of education in two Latin American countries, Argentina and Colombia, aiming to decipher how, from their very origins as nations, the intention to strengthen nationality and citizenship was used to exclude, erase or subordinate the integration of populations and cultures that were not considered part of the nation. It also points out the limitations to the analysis from the history of education in Latin America to account for and sufficiently problematize the racist and exclusionary correlative with indigenous people and the black and African descendant communities. Finally, the paper offers a reading on the lines of research and contributions of different authors to analyze this problem based on the textbooks.

\section{Resumo}

O presente artigo centra-se na história da educação em dois países latino-americanos: a Argentina e a Colômbia, para decodificar como, desde suas origens como nação, a intenção de consolidar a nacionalidade e a cidadania foi utilizada para a exclusão, a invisibilização ou a integração subordinada das populações e culturas que não eram consideradas parte da nação. Além disso, são assinaladas as limitações nas análises desde o campo da história da educação na América Latina, para dar conta e problematizar o discurso racista e excludente com os povos indígenas e as comunidades negras e afrodescendentes. Finalmente, oferece-se uma leitura sobre as linhas de pesquisa e contribuições que diversos autores fizeram para analisar esta problemática desde os textos escolares.

Fecha de recepción: 25 de julio de 2016 / Fecha de aprobación 27 de agosto de 2016
Palabras clave

historia de la educación; enfoque civilizatorio; exclusión; racismo; diversidad cultural

Keywords

history of education; civilizational approach; exclusion; racism; cultural diversity

\section{Palavras chave}

história da educação; abordagem civilizatória; exclusão; racismo; diversidade cultural

\footnotetext{
* Consejo Nacional de Investigaciones Científicas y Técnicas, Conicet / Universidad Nacional de Tres de Febrero, Argentina.

Correo electrónico: annyocoro@hotmail.com
} 


\section{Introducción}

En América Latina la escuela moderna emergió en las últimas décadas del siglo XVIII como una institución de gran importancia, entramada con la historia de la ilustración y la modernidad (Finocchio, 2012). En el siglo XIX, en las nacientes naciones latinoamericanas, la escuela emprende su trasegar bajo el mandato civilizatorio que proclamaba la homogenización, el sentido de pertenencia a la nación y la búsqueda del orden social como condición para insertar la nación en la modernidad.

Bajo la promesa de la integración a ese ideal, el sistema educativo se pobló de dispositivos disciplinarios que instituyeron lo legítimo y lo deseable, pero al mismo tiempo desautorizaron aquellas diferencias culturales consideradas por fuera de la norma aceptada. De esta manera, al afirmar los valores modernos de civilización y definir a los sujetos portadores de estos, se construía la representación de un otro que pasó a ser el bárbaro, el salvaje que debía ser encauzado para integrarse a la vida civil. Solo así podía afirmarse la hegemonía del imaginario civilizatorio moderno.

En el campo de la historia de la educación en América Latina existen importantes estudios relativos al nacionalismo y las políticas educativas del siglo XX. En la mayoría de estos trabajos podemos encontrar al menos tres rasgos que nos permiten adentrarnos en el problema que plantearemos a continuación. En primer lugar, la escuela se constituyó en el más importante dispositivo para promover valores, emblemas, ideas y símbolos, y así construir la identidad nacional de los países. Un segundo rasgo se refiere al papel de la pedagogía y los saberes escolares en la difusión de la historia y la geografía nacional, como elementos centrales para la construcción de las ciudadanías en la primera mitad del siglo Xx. En tercer lugar, la promoción de culturas escolares cuyos rituales y prácticas apuntaron a cimentar patrones cívicos. Si bien el campo de la historia de educación en América Latina ha mostrado el papel de la escuela en materia de construcción de la nación y la nacionalidad, encontramos que lo ha hecho sin problematizar lo suficiente el correlato racista y excluyente hacía las poblaciones y culturas que no eran consideradas parte constitutiva de la nación: los pueblos indígenas y las comunidades negras o afrodescendientes.

\section{La nación y sus “otros” en América Latina}

Tanto en la época colonial como durante su vida independiente, las sociedades latinoamericanas crearon sistemas de diferenciación y jerarquías raciales que otorgaban privilegios a blancos y mestizos. La identidad colectiva nacional se fundamentó en la exclusión de algunos segmentos de la población, configurando un orden racial con clara desventaja para el negro y el indígena. Este desigual orden racial ha marcado la historia de afrodescendientes e indígenas, negándoles no solo el acceso a derechos igualitarios sino también minando el desarrollo de su identidad cultural.

El mestizaje y la democracia racial se convirtieron en el discurso representativo de la identidad de la naciones latinoamericanas; así, se buscaba invisibilizar a las poblaciones indígenas y negras, y a "reafirmar la supremacía cultural, y a veces biológica, de herencias blancas hispánicas" (Reyes-Santos, 2008, p. 21). El discurso hegemónico del mestizaje se convirtió en una herramienta que, al tiempo que alimentaba el imaginario de nación progresista pensado por las élites, contribuyó a ocultar los conflictos culturales y racistas de la sociedad. En consecuencia, el mestizaje puede ser visto como "un constructo ideológico hegemónico, a la vez patriarcal y colonial" (Rivera, 2010, p. 134), que se desarrolla paralelo al deseo de las élites de afirmarse en los territorios heredados de las luchas de independencia y de buscar un mayor despojo de la tierra que liquidara a indígenas y negros.

\section{Argentina: el discurso hegemónico de "civilización o barbarie"}

A partir de la Constitución de 1853 se inicia periodo denominado la Organización Nacional, que se extiende hasta la década de 1880. Desde mediados de esa década el gobierno inició campañas para la llegada masiva de inmigrantes a Argentina, estimulando su ingreso a través de distintos programas de apoyo. Aunque el interés por la nacionalidad se encuentra también en otros momentos de la historia argentina, en la década de 1880 la nacionalidad se convirtió en el centro de las preocupaciones de los grupos dirigentes (Bertoni, 2001). 
Las élites celebraban el aumento considerable de la población inmigrante en el país y veían con admiración el mejoramiento de la raza que su origen europeo aportaba a la Argentina. En la naturaleza del proyecto de nación que se estaba gestando, la inmigración haría posible expandir la raza blanca por todo el territorio para que pudiera surgir una próspera nueva Argentina. Se puso, entonces, en marcha un proyecto de negación del pasado anclado en el discurso de la antinomia civilización y barbarie como motor de cambio, basado en principios eurocéntricos y excluyentes para regir la sociedad.

Este proyecto de nación, que tuvo en Domingo Faustino Sarmiento, considerado el padre del sistema educativo argentino, a uno de sus principales gestores, no contemplaba la inclusión de indígenas ni de negros. De acuerdo con esta concepción la inmigración permitiría que la Argentina se diferenciase de los otros países de la región, superando la barbarie y la inferioridad representada en negros e indígenas. De esta manera, las élites fueron receptivas y difundieron las ideas racistas de la Europa positivista, asumiendo que estos grupos debían ser combatidos, pues eran la representación del subdesarrollo y del atavismo étnico. Esta exclusión oficializada se llevó a cabo a través de la estigmatización, eliminación o la integración subordinada de segmentos sociales. Se trataba así de hacer a un lado, de confinar al exterminio y al olvido a quienes eran considerados un obstáculo para el desarrollo de la nación, de ahí que los negros fueron considerados como un pasado remoto y desaparecido, y el indígena aparecía como el vencido, el derrotado por la guerra de exterminio llamada la conquista del desierto (Ocoró Loango, 2010)1.

Sarmiento (1883) anunciaba en su libro Conflictos y armonías de las razas en América que la población negra pronto desaparecería como "raza". Así lo expresaba:

1 Se conoce como Conquista del Desierto a la campaña militar que Ilevó a cabo el gobierno argentino entre 1879 y 1885, con el objeto de expandir su dominio sobre los territorios del sur de Buenos Aires, Río Negro y Neuquén hasta los ríos Negro y Neuquén. En realidad se trató de un plan de aniquilamiento que tuvo como resultado miles de indios muertos o condenados al desarraigo y la servidumbre. En este mismo contexto, desde 1870 hasta principios del siglo XX, el Estado nacional emprendió la ocupación militar del Chaco Argentino, región que estaba habitada por distintas etnias indígenas, apropiándose de esos territorios.
Y sin embargo, la naturaleza misma, la acción secreta y latente de las afinidades y de las repulsiones, viene obrando en silencio, sin plan y como por instinto, hasta que un día, echáis la vista en torno vuestro, y no veis hijos de los conquistadores, ni negros esclavos, los unos en camino de desaparecer, los otros extinguidos en menos de medio siglo en toda la América española, pues en Chile no hay uno, en Lima poquísimos, y de Méjico, Wilson, hablando de negros, dice que habla de oídas, porque no ha visto ninguno. De Buenos Aires en veinte años más, será preciso ir al Brasil para verlos en toda la pureza de su raza. (p. 44) (resaltado por fuera del texto original).

El deseo de excluir a estos grupos también se manifestará en los censos de población realizados a partir de la segunda mitad del siglo XIX. Estos se convirtieron en una herramienta que alimentaba el imaginario de nación deseada, pensado por las élites y contribuyó a ocultar o invisibilizar a los grupos étnicos. Como bien señala Andrews (2016),

[...] las naciones latinoamericanas realizaron esos censos bajo la sombra del racismo científico que por ese entonces era absolutamente hegemónico en el mundo occidental y eso, claro está, pronosticaba un sombrío futuro para aquellas naciones cuyas poblaciones eran en su mayoría o en una minoría mayor, no blancas. Buscando desmentir esos pronósticos, todas las naciones en la región trataron de blanquear su composición racial atrayendo inmigrantes europeos. (p. 260).

En Argentina, los censos de 1869 y 1895 celebraban de manera continua la inmigración y el aumento de la raza blanca en el país, mostrando las concepciones eurocéntricas y racistas a las que adherían. El censo de 1895 expresaba:

Habiendo llegado al país desde 1857 dos millones y medio de europeos, y contando hoy la República con cuatro millones de habitantes, se comprende que casi la totalidad de la población pertenece a la raza blanca. Quedan, sin embargo, principalmente en la provincia de Corrientes, en Salta y Jujuy y en el territorio de la Pampa, algunos 
últimos representantes de las razas aborígenes, puras, aunque ya completamente sometidas a la civilización. (De la Fuente y Carrasco, 1898, p. XLVIII) (resaltado por fuera del texto original).

\section{La escuela al servicio de la "nueva nación"}

Desde finales del siglo XIX, la Argentina vivía una realidad cultural y política heterogénea cuya diversidad de lenguas, tradiciones, culturas políticas, producto de la inmigración, amenazaba con disgregar la población. Al país arribaban inmigrantes provenientes de zonas con menor desarrollo al esperado, y aun cuando el interés estaba centrado en estimular el ingreso de inmigrantes del norte de Europa, la inmigración realmente atrajo, masivamente al país, población proveniente de los países del sur (Tedesco, 1986).

Las tensiones, las críticas y los primeros brotes de rechazo a los inmigrantes no esperados se hicieron sentir en diferentes sectores de la sociedad, lo que puso de manifiesto las dudas sobre su integración generó desconfianza hacia ellos. El inmigrante esperado, aquel laborioso y emprendedor que cambiaría el futuro económico del país, estaba ahora puesto bajo el panóptico, era mirado de manera crítica y con matices negativos (Bertoni, 2001). La simpatía con la que eran recibidos los inmigrantes cede lugar a la desconfianza y ganan terreno las ideas y críticas que señalaban los nexos entre el aumento de la criminalidad y la inmigración (Scarzanella, 1999).

La preocupación también se trasladó a la enseñanza que impartían las escuelas de los inmigrantes a sus hijos, ya que estos los educaban conforme los valores de sus países de origen, en detrimento del amor a la patria Argentina. A esto se suma la tendencia de algunos de no nacionalizarse, lo que hacía posible que sus hijos nacidos en la Argentina conservaran la nacionalidad de sus padres. Esta tensión se expresa claramente en un apartado titulado "Italianos y escuelas italianas" de la revista El Monitor:

Ocurre con frecuencia que la prensa se ocupa de las escuelas particulares, y con especialidad de las que denominan italianos: generalmente se forman dos bandos, uno mal intencionado, que se propone, animado de un patriotismo egoísta y extraviado, arrancar del corazón de los argentinos nativos, el natural sentimiento de amor a la patria, en nombre del que ellos tienen a la suya, no respetando en sus hijos la tendencia natural, de querer el pedazo de tierra en que nacen, donde reciben las primeras dulces impresiones de la vida, y donde seguramente pasarán el resto de sus días, aspirando una más elevada atmósfera, y jugando un rol más importante y notorio, que aquel que desempeñaran sus padres en la propia tierra: del otro lado se pone el grito en las nubes, se cree comprometido el porvenir, se denuncian proyectos de absorción y conquista, se ve ultrajada la soberanía nacional porque se destinan algunos, muy pocos, miles de liras para subvencionar las escuelas que una o dos asociaciones italianas costean, desde hace muchos años, en la ciudad de Buenos Aires, y algunos puntos de la campaña de la provincia en el mismo nombre. (Revista el Monitor, 1888).

Pese al clima generado, la inmigración seguía apareciendo como necesaria para lograr el progreso de la nación. No obstante, la nacionalidad no podía dejarse al azar, lo que hacía necesario decisivas acciones del Estado para generar la adhesión de los extranjeros a la patria. La escuela fue interpelada ante su rol de transmisora de la cultura nacional, lo que se expresó en la Ley Nacional de Educación (1420) de 1884, en la que se planteaba que la educación debía responder a

[...] un principio nacional en armonía con las instituciones del país, prefiriendo la enseñanza de materias como la historia nacional, la geografía nacional, el idioma nacional y la instrucción cívica de acuerdo con el régimen político del país, armonizando esa enseñanza con las condiciones de la sociedad [...] (Salvadores, 1941, citado por Bertoni, 2001, p. 43).

En ese mismo periodo, la revista El Monitor (1887) anunció nuevos lineamientos para mejorar la enseñanza, la asistencia de los niños a las escuelas y la creación de una comisión encargada de reformar los planes de estudio "en pro de la gran causa de la educación que labra pacientemente el cimiento de la nacionalidad" (pp. 331-334). A partir de ahí, la enseñanza de la historia patria adquirió más relevancia, 
así como la celebración de las fiestas patrias en los actos escolares para lograr trascendencia en el conjunto de la sociedad (Bertoni, 2001). Todo esto condujo a que se tomaran medidas para centralizar y uniformar el sistema educativo e instalar distintos dispositivos para difundir la identidad de nación y el amor a la patria, para una población a la que en parte le era ajeno.

El libro de texto y las efemérides escolares fueron acompañando el proceso de formación de la identidad nacional y el ejercicio de valores cívicos en la escuela, afirmando el relato del pasado diseñado por las élites. A través del contorno definido por Sarmiento y la escritura de Bartolomé Mitre, se fue narrando un pasado en el que la gesta de mayo de 1810 emergía como el hito fundador de la nación (Romero, 2004). Esta visión del pasado sería reforzada y refinada a principios del siglo XX por los historiadores de la Nueva Escuela Histórica, constituyendo, a mediados del siglo xx, la versión del pasado más ampliamente aceptada, al punto que su larga hegemonía estaba claramente expresada en los textos escolares de historia (Romero, 2004). El revisionismo histórico de las primeras décadas del siglo $\mathrm{XX}$, aun cuando revindicó héroes nacionales denostados por la historia oficial y logró llegar y arraigar en la sociedad, tuvo un impacto menor en los libros de texto (Romero, 2009).

Este relato vencedor del pasado fue celosamente guardado, sostenido y renovado por la escuela. Esta última lo incorporó en su hacer y lo asumió como parte de su tarea innata. Al hacerse cargo de conservar el pasado en la memoria social, a través de resguardar sus símbolos, valores y saberes, la escuela cumplió un papel importante en la configuración del imaginario de la nación de las élites.

\section{Colombia: el destino de la educación en medio de las disputas ideológicas}

Durante el siglo XIX, los partidos políticos Liberal y Conservador, y la Iglesia católica, alineada a aquellos, marcaron el desarrollo de educación en Colombia. El destino de la educación se va ver afectado decididamente por la manera como estos resolvieron sus tensiones (Ramírez y Téllez, 2006) y va a marcar la postura del Estado frente a la regulación o no de la educación.
Con el Decreto Orgánico de Instrucción Pública de 1870, sancionado durante la presidencia del liberal Eustorgio Salgar, se estableció la educación pública, obligatoria, laica y gratuita en Colombia. La norma expresaba los intereses reformistas de los sectores liberales que postulaban la neutralidad ideológica, la obligatoriedad y la responsabilidad del Estado como pilares de la educación. También organizó en forma minuciosa el sistema educativo nacional y constituyó "uno de los documentos más importantes de la historia educativa de Colombia" (Jaramillo, 1980, p. 80).

Los tradicionales sectores conservadores y eclesiásticos, que tenían amplias disputas ideológicas con los sectores liberales, se resistían a la universalización y al laicismo de la educación que el decreto proclamaba. Además, la educación no era tenida como un bien a reivindicar por todos los sectores populares ya que, en muchos casos, significaba la interrupción del sustento familiar que el trabajo de los niños aportaba. Estas tensiones van a ser dirimidas con la Guerra Civil de 1876, la cual implicó el cierre de escuelas y la pérdida de la vida de muchos maestros. Los fondos presupuestales asignados a la educación fueron destinados a financiar la guerra (Cataño, 2005).

\section{Como bien apuntan Ramírez y Téllez (2006),}

[...] la incapacidad y rivalidad de los partidos políticos por organizar y regular la educación a lo largo del siglo XIX, las guerras civiles y los escasos recursos con que contaba el país, Ilevaron a que Colombia a comienzos del siglo xx fuera uno de los países más atrasados del mundo en materia educativa. [...] la tasa de analfabetismo como porcentaje de la población adulta en Colombia (66\%) se encontraba en 1900 entre las más altas de América Latina. De hecho, Colombia tenía un $20 \%$ más de personas analfabetas que Argentina. (p. 5).

A partir de 1886, el proyecto político conservador logra el poder y la segunda administración de Rafael Núñez instituye un nuevo orden constitucional. Se sella así una alianza entre el Estado y la Iglesia católica que elimina la reforma liberal educativa y reinstaura la obligatoriedad confesional católica en todo el territorio nacional. En este nuevo pacto constitucional, que rigió el país 
por más de un siglo, resurgía con fuerza el discurso colonialista. De esta manera la Constitución de 1886 "(...) constituye un retorno a la tradición hispanista y el tiempo de la filosofía tomista. La nación colombiana es percibida (...) blanca, católica y cuya lengua natural es el habla castellana. Allí no se hace mención a los otros grupos étnicos" (Pineda, 1997, p. 113).

Posteriormente, la Ley 89 de 1890 delega a la Iglesia, a través de las misiones, la educación de los pueblos indígenas y gran parte de la administración de sus territorios. En esta ley, los pueblos indígenas aparecen calificados como salvajes sin capacidad de autogobierno y requieren del tutelaje eclesiástico y de los poderes locales y regionales. La ley distingue, por un lado entre, "los salvajes que vayan reduciéndose a la vida civilizada por medio de Misiones" y por otro, a "las comunidades de indígenas reducidas ya a la vida civil". Declara, también, que el gobierno y la autoridad eclesiástica acuerdan la forma en que estos grupos serán gobernados, ya que la Ley General de la República no se aplicará sobre estos.

El Concordato de 1887, consecuencia de la reciente instituida Constitución Política, otorgó amplios privilegios a la iglesia. En principio reconoció la religión católica como religión oficial de la República y garantizó su protección, además le otorgó múltiples beneficios y exenciones tributarias y fiscales. No obstante, lo que más nos interesa, a efectos de nuestro análisis, es que la educación pública en escuelas, colegios y universidades, de ahí en más, debió regirse de acuerdo con la Iglesia católica y esta se haría cargo de la evangelización de los salvajes indígenas. Sin duda, el concordato ponía en evidencia "el resurgimiento de una alianza que había demostrado su efectividad durante el período de colonización europea: Estado e Iglesia como agentes civilizadores" (Castillo y Rojas, 2005, p. 35). Al mismo tiempo, los afrodescendientes no eran considerados ya que dentro del imaginario de las élites, los territorios nacionales estaban habitados solo por indígenas (Helg, 2004).

El hecho de que la población negra no haya sido contemplada desde el criterio definido para los pueblos indígenas, muestra cómo esta población era desconocida y, en muchos casos, invisible a los ojos de las élites y del Estado de derecho. Esto no supone que el Estado haya apostado al desarrollo de los pueblos indígenas, por el contrario, mostraba la minusvalía e interiorización desde la cual eran caracterizados. De hecho, ni a negros ni a indígenas se les reconocía como sujetos hacedores y portadores de cultura. Más bien, para las élites

[...] indígenas y negros fueron representados como "salvajes", no civilizados, que deberían ser progresivamente incorporados a la nación, lo que nuevamente supone una forma de representación de estas poblaciones construida al margen de sus propios intereses y con un claro objetivo de sujeción. (Castillo y Rojas, 2005 p. 35).

Esta negación también supuso la represión a sus formas de expresión, su historias y sus lenguas dado que "hasta bien entrado el siglo $x x$, la escuela mantuvo la prohibición borbónica del uso de las lenguas aborígenes (incluyendo las indígenas, la palenquera de San Basilio o la variedad anglófona de los raizales de San Andrés)" (Romero-Medina, 2010, p. 172).

Las propuestas racistas adoptadas por la intelectualidad argentina también hicieron eco en sectores intelectuales colombianos preocupados por frenar la supuesta decadencia de la raza colombiana (Uribe, 2008). Uno de los que se inspiró en la experiencia argentina para analizar la cuestión racial en Colombia fue el médico Miguel Jiménez López y, en menor medida, Luis López de Mesa (Uribe, 2008). Este último se mostró a favor de promover la inmigración como una salida para mejorar la composición racial de la población, para, de esta manera, lograr que Colombia saliera del atraso histórico en el que estaba sumida. Sin embargo, en Colombia, las propuestas de ingreso de inmigrantes no se comparan con las acontecidas en Argentina. Más bien el intento por desarrollarla fue tardío y fracasó.

En la siguiente cita de 1928, del Archivo Histórico de Cartagena-Colombia, podemos apreciar cómo se menciona a Colombia como un país que aunque no había logrado la desaparición de la negritud como en Argentina y Chile, no tenía altos porcentajes de población indígena como Perú y Ecuador. Colombia aparecía como un país en donde el relato del mestizaje emergía como discurso hegemónico de la identidad nacional: 
Entre nosotros no ocurre, como en la Argentina y en Chile en donde todo vestigio del hombre africano ha desaparecido. Tampoco tenemos la situación del Perú y el Ecuador, en donde el elemento blanco no alcanza el 6 por ciento de la población, mientras el elemento indio sube al 70 y el resto se divide entre africanos y mestizos. Somos un pueblo en donde el mestizo (mezcla de español e indio), es preponderante. (Archivo Histórico de Cartagena, 1928, citado por Hinestroza, 2011, p. 76) (resaltado por fuera del texto original).

El deseo de mejorar la raza iba de la mano con las conceptualizaciones racistas de la época que exaltaban las políticas de inmigración llevadas a cabo por países como Argentina, Uruguay y Chile, y motivaban a la eliminación de la negritud por ser considerada inferior y no apta para el desarrollo. Los argumentos presentados por el Archivo Histórico de Cartagena, en junio de 1928, en las dos citas que reproduciremos a continuación, son bastante ilustrativos:

En las naciones de América, donde preponderan los negros, reina también el desorden. Haití es el ejemplo clásico de la democracia turbulenta e irremediable. En los países donde el negro ha desaparecido como en la Argentina, Chile y Uruguay, se ha podido establecer una organización económica y política con sólidas bases de estabilidad. El mulato y el zambo son los verdaderos híbridos de América. Nada les debe a ellos la cultura americana. Ayarragaray afirma que los hijos de la unión de negros con zambos o con indios son inferiores a sus padres por la inteligencia y por la fuerza física; tienen una voluntad débil, dominada por pasiones groseras; a la flaqueza de carácter unen una inteligencia poco lúcida, incapaz de análisis profundo de método, de ideas generales, el amor al bullicio, el hábito de hablar a gritos, cierta abundancia oratoria y una retórica pomposa, que es precisamente lo que se Ilama "tropicalismo". (Archivo Histórico de Cartagena, 1928, citado por Hinestroza, 2011, p. 74) (resaltado por fuera del texto original).

Tanto indígenas como negros fueron considerados razas inferiores, bárbaras y primitivas. Este modelo reduccionista, racista y segregador es el que luego se emplea para calificar y definir al Caribe y sus gentes (Hinestroza, 2011).

Otros primitivos pobladores de nuestro territorio fueron los africanos que los españoles trajeron para explotar con ellos a la naturaleza áspera y huraña. El espíritu del negro, rudimentario e informe, como que permanece en una perpetua infantilidad. La huma de una eterna ilusión lo envuelve y el prodigioso don de mentir es la manifestación de esa falsa imagen de las cosas, de la ofuscación que le produce el espectáculo del mundo, del terror de hallarse abandonado y disminuido en el concierto humano.

La otra raza salvaje, la raza indígena de la tierra americana, segundo de los elementos bárbaros de nuestra civilización, ha transmitido a sus descendientes el pavor de su vencimiento. En el rencor de la derrota, parece haberse refugiado en el disimulo taciturno y la cazurrería insincera y maliciosa. Afecta una completa indiferencia por las palpitaciones de la vida nacional, parece resignada a la miseria y a la insignificancia. Está narcotizada por la tristeza del desierto, embriagada con la melancolía de sus páramos y sus bosques. (Archivo Histórico de Cartagena, 1928, citado por Hinestroza, 2011, p. 74).

En Colombia, el discurso higienista de principios de siglo Xx apeló a la genética y a la geografía para justificar la exclusión o la inclusión de los distintos grupos de la población (Hinestroza, 2011). Estos intelectuales veían la composición racial colombiana como el resultado de la influencia del clima y de la geografía, en la cual la jerarquía geográfica o territorial y climática del centro andino, por su gran mayoría de habitantes blancos, se contraponía a las Ilanuras y trópicos habitadas por poblaciones inferiores de indígenas y negros (Flórez, 2008).

En sus discursos los grupos étnicos fueron vistos como problemas y algunos grupos fueron situados en el centro de la degeneración racial y como receptores de las medidas higienistas. Bajo este discurso eugenésico, la población de la costa del Caribe no fue valorada dentro del ideal nacional. Sus gentes fueron señaladas como 
portadoras de una cultura inferior y como una raza biológica no apta para el desarrollo del país.

Aunque en la vida colonial y republicana, las poblaciones indígenas y afrodescendientes no fueron insertas en los tradicionales procesos de escolarización, sí hubo, como bien lo marcan Castillo y Rojas (2005), un dispositivo de evangelización orientado, por la Iglesia, no solo a la conversión moral, sino también para hacer de estas poblaciones seres aptos para la vida en la nación. La educación de las poblaciones rurales indígenas y negras continuó bajo el control de la Iglesia católica hasta finales del siglo XX, cuando se promulga la Constitución Política de 1991 (Romero, 2010).

En Colombia la educación de los otros se desarrolló desde una fuerte impronta evangelizadora. Por supuesto, tanto

[...] la escuela en la Argentina, como en Europa, no nació dentro de un sistema gobernado por el Estado, y [...] lo escolar entendido como un espacio-tiempo social autónomo deviene de una mezcla entre religión y ciencia que los requerimientos de cristianización plantearon en los siglos XVI, XVII y XVIII". (Finocchio, 2013, p. 220).

Sin embargo, en Colombia, este dispositivo evangelizador nos obliga a reconocer las prácticas de escolarización/ evangelización y aculturación que se dieron en paralelo con el desarrollo del sistema educativo nacional ya que, mientras que para aquellos ciudadanos considerados nacionales se pensaba un proyecto moderno, ilustrado que nacía ya sin integrar a los otros, para negros e indígenas la colonización sería perpetuada.

\section{Textos escolares y racismo epistémico}

En la última década, diversos estudios se han ocupado de la representación de indígenas y afrodescendientes en los textos escolares en América Latina. Herrera, PiniIla y Suaza (2003), por ejemplo, analizan para el caso colombiano, cómo los textos escolares del periodo de 1900 a 1950 muestran una visión negativa del pasado de los pueblos indígenas y los negros son considerados ajenos a la colombianidad. En un ejercicio similar, Garrido (2009) refiere cómo en Chile los contenidos de los textos escolares sostienen una memoria racista que excluye a los grupos indígenas e impone una mirada de superioridad de los grupos blancos.

Soler (2008) ha mostrado, también para el caso colombiano, cómo la exclusión y el prejuicio hacia indígenas y afrodescendientes son legitimados a través de los textos de ciencias sociales y reflejan solo a blancos y mestizos, borrando de la historia y de las estadísticas a indígenas y afrodescendientes. A similares conclusiones Ilega Granda (2000), para el caso ecuatoriano, quien describe cómo los textos escolares de algunas editoriales jerarquizan y racializan la diversidad cultural ecuatoriana. En la misma dirección, el trabajo de Mena (2009) muestra cómo las ilustraciones de los textos que representan a los afrocolombianos no dignifican a estos grupos, sino que, más bien, los racializan. Cucuzza (2007) resalta el papel reducido que tienen los negros en los textos escolares argentinos. Estos solo aparecen en acontecimientos históricos puntuales como las invasiones inglesas, en el rol heroico de soldados que combatieron por la patria o en algunos sucesos de las guerras de independencia. También predomina la condición vendedores ambulantes o sirvientes en el periodo colonial, desmereciendo otras actividades desarrolladas por estos (Balsas, 2011).

Los textos escolares fueron centrales en la configuración de imaginarios y referentes sobre la nación. Estos no han sido neutros, muy por el contrario, han propuesto una lectura eurocéntrica de las sociedades latinoamericanas, en las que el desarrollo, los avances tecnológicos, la democracia y el conocimiento siguen siendo presentados como un atributo del hombre blanco, civilizado. Contrariamente, los indígenas y afrodescendientes aparecen relegados de los imaginarios de desarrollo y de las actividades productivas. Estos han sido visibilizados como seres exóticos, conflictivos o salvajes (Soler, 2008) y de modo antagónico al nosotros nacional. A estos grupos, en general, no se los representa dentro de espacios de decisión, de progreso o de profesionalismo. Solo aparecen cuando se menciona la esclavización, o en relación a problemas de desplazamiento, discriminación, pobreza y subdesarrollo o por su desempeño en actividades deportivas siempre por fuera de la historia nacional (Soler, 2008; Balsas, 2011). 
A partir de estas discusiones podemos destacar cómo los indígenas y negros son representados en los textos escolares a través de estereotipos culturales, que refuerzan el racismo estructural propio de las sociedades latinoamericanas. También refuerzan el mito del mestizaje y sus análisis diluyen el problema del racismo. Las lecturas que se hacen sobre el racismo y la discriminación son reduccionistas y carecen de una perspectiva estructural de los fenómenos raciales. El racismo es, en muchos casos, reducido a un asunto psicológico cuando no es mostrado solo en contextos históricos lejanos como el apartheid en Sudáfrica o el Ku Klux Klan en Estados Unidos (Soler, 2008) y no como parte de la dura realidad que enfrentan estas poblaciones en la región.

En la lectura que los textos escolares hacen de la historia africana esta pareciera ser solo la historia de la esclavización y la manera como estos pueblos fueron inferiorizados. De la opresión a la que fueron sometidos y de la continuidad del racismo y la discriminación, heredados de ese proceso, poco se habla. Hay silencios, miradas parciales o tergiversadas como si la esclavización fuese su única historia, borrando la vida cultural, política y económica de estas poblaciones y sus aportes a la historia de la humanidad.

Los estudios sobre estos manuales y sus contenidos nacionalistas permiten afirmar la existencia de un racismo epistémico que clausuró en el lugar del estereotipo y la subalternidad a las poblaciones y las culturas de origen africano. La historia escolar fue un medio muy poderoso para promover la idea de la supremacía racial blanca y reproducir la dominación cultural hacia estos grupos. La mayoría de los textos de uso escolar expresan el ideal eurocéntrico, ayudando a sostener el epistemicidio de los saberes y las historias de los grupos subalternos. Los textos escolares reproducen, legitiman y trasmiten valores e ideologías de los grupos dominantes (Apple, 1979).

El texto escolar no ha logrado un quiebre con la representación eurocéntrica y la subalternización de indígenas y negros. Estos han reflejado la historia subordinada a las interpretaciones de grupos hegemónicos e intereses políticos que construyeron la historiografía latinoamericana. Esto también tiene que ver con la forma como los estudios académicos han marginado y excluido el tema negritud y reabre la memoria sobre la deuda que los sistemas educativos y la sociedad latinoamericana en su conjunto tienen con estas poblaciones.

Habría que agregar que, pese a la centralidad que los libros de texto tienen dentro del aula, muy poco han sido transformados o tocados por los desarrollos de las teorías y las pedagogías críticas del presente. Aun cuando las nuevas tecnologías desafían este formato, el libro de texto sigue ocupando un lugar muy importante en el sistema escolar vigente, por cuanto se lo asume como la condensación del saber, la garantía de aprender contenidos y como el currículo que la escuela desarrolla para que los chicos aprendan. Valdría la pena entonces encaminarnos a construir desde este dispositivo una sociedad justa y equitativa con la historia pasada y presente de los afrodescendientes.

\section{Conclusiones}

En América Latina, la escuela ha desempeñado un papel muy importante en la consolidación del proyecto de nación imaginado por las élites. Desde su nacimiento, ha sido un espacio de transmisión cultural y de socialización de los sujetos en los valores aceptados y legitimados para el conjunto social. A través de distintos dispositivos pedagógicos, ha cumplido una función mediadora y simbólica en la construcción de ciudadanía y la formación de identidades nacionales. Sin embargo, desde su impronta fundacional ha contribuido a subalternizar a las culturas indígenas y negras, trasmitiendo jerarquizaciones de clase e ideas racistas que sostienen un orden racial.

El texto escolar ha reforzado los imaginarios de la nación blanca y homogénea, y en muchos casos, excluye la diversidad étnica de los países presentándolos como mayoritariamente blancos y mestizos. Difícilmente podremos abrir un real diálogo intercultural si la historia de la población negra e indígena sigue silenciada o contada desde los ojos del relato oficial eurocéntrico hegemónico. 
Andrews, G. (2016). Los afrodescendientes en los censos latinoamericanos, 1776-2011. Claves. Revista de Historia, 2, 257-278. Montevideo.

Apple, M. (1979). Ideología y currículo. Barcelona: Akal.

Artieda, T., Liva, Y. y Almirón, S. (2011). Textos escolares para la educación bilingüe intercultural: omisiones estatales y empeños indígenas (Chaco, Argentina, 1987-2007). Boletín de Antropología y Educación, 2(03), 27-34.

Balsas, M. (2011). Negritud e identidad nacional en los libros escolares argentinos: Del surgimiento del sistema nacional de educación al bicentenario. Estudios Sociológicos, 29(86), 649- 686 .

Bertoni, L. (2001). Patriotas, cosmopolitas y nacionalistas. La construcción de la nacionalidad argentina a fines del siglo XIX. Buenos Aires: Fondo de Cultura Económica.

Castillo, E. y Rojas, A. (2005). Educar a los otros. Estado, políticas educativas y diferencia cultural en Colombia. Popayán: Universidad del Cauca.

Cataño, G. (2005). Los radicales y la educación Revista Credencial Historia, 66. Recuperado de http://www.banrepcultural.org/ blaavirtual/revistas/credencial/junio1995/junio2.htm Bogotá: Biblioteca Virtual del Banco de la República.

Cucuzza, R. (2007). Yo argentino: la construcción de la nación en los libros escolares (1873-1930). Buenos Aires: Miño y Dávila.

De la Fuente, D. (dir.) (1872). Primer Censo de la República Argentina-1869. Buenos Aires.

De la Fuente, D. y Carrasco, G. (dir.) (1898). Segundo Censo de la República Argentina-1895. Tomos I, II y III. Buenos Aires.

Finocchio, S. (2012). América Latina: nuevos rumbos en los saberes educativos. Boletín de la Biblioteca del Congreso de la Nación, 126, 103-115. Buenos Aires.

Finocchio, S. (2013). El papel de la educación en la invención de lo social (o de cómo la historia escolar transformó progresivamente lo social en la Argentina). Revista de Indias, LXXIII (257), 219-238.

Flórez, F. (2008). Representaciones del caribe colombiano en el marco de los debates sobre la degeneración de las razas: geografía, raza y nación a comienzos del siglo xx. Historia y Espacio Revista 31, 35-59. Cali: Departamento de Historia de la Universidad del Valle. julio-diciembre.

Garrido, C. (2009). Mi vecino, ¿mi enemigo? Nacionalismo en los textos escolares de historia de educación básica en Chile (1981-2006). Seminario Internacional Textos Escolares de Historia y Ciencias Sociales. Santiago de Chile: Ministerio de Educación.

Granda, S. (2000). Textos escolares e interculturalidad: la representación de la diversidad cultural ecuatoriana. Programa de Maestría en Estudios Latinoamericanos Mención en Estudios de la Cultura. Universidad Andina Simón Bolívar, sede Ecuador.

Helg, A. (2004). Constituciones y prácticas sociopolíticas de las minorías de origen africano, una comparación entre Colombia y Cuba. En: J. Arocha (comp.). Utopía para los excluidos. El multiculturalismo en África y América Latina (pp. 23-45). Bogotá: Universidad Nacional de Colombia, CES.
Herrera, M., Pinilla D., A.V. y Suaza, L.M. (2003). La identidad nacional en los textos escolares de Ciencias Sociales. Colombia 1900-1950. Bogotá, D.C.: Universidad Pedagógica.

Hinestroza C., I.D.C. (2011). Racismo en el discurso higienista inspirado en las ideas eugenésicas, Cartagena 1919-1922: una aproximación desde el análisis crítico del discurso (ACD). Trabajo de grado para optar el título de historiadora. Cartagena, Colombia: Universidad de Cartagena, Facultad de Ciencias Humanas.

Jaramillo, J. (1980). Decreto Orgánico de Instrucción Pública del 1 de noviembre de 1870. Revista Colombiana de Educación, 5, 80-121.

Ley 89. Por la cual se determina la manera como deben ser gobernados los salvajes que vayan reduciéndose a la vida civilizada. Congreso de Colombia. Bogotá, Colombia, 25 de noviembre de 1890.

Mena, M. (2009). La ilustración de África, los africanos y las africanas en los textos escolares de ciencias sociales. Rasgos para el caso colombiano. Seminario Internacional Textos Escolares de Historia y Ciencias Sociales. Santiago de Chile: Ministerio de Educación.

Ocoró, A. (2010). Afroargentinidad y memoria histórica: la negritud en los actos escolares del 25 de mayo. Tesis de Maestría. Flacso. Sede Académica Argentina, Buenos Aires. Recuperado de http:// www.flacsoandes.org/dspace/handle/10469/2997.

Pineda, R. (1997). La Constitución de 1991 y la perspectiva del multiculturalismo en Colombia. Revista Alteridades, 7(14), 107-129.

Ramírez, M. y Téllez, J. (2006). La educación primaria y secundaria en Colombia en el siglo xx. Borradores de Economía, 379.

Revista el Monitor, VI, (1887).

Revista el Monitor No. 130 (abril de 1888). Italianos y escuelas italianas.

Reyes-Santos, I. (2008). Capital neoliberal, raza, migración: análisis comparativo de relaciones domínico-haitianas y domínicopuertorriqueñas. Revue Européenne des Migrations Internationales, 24(1), 13-34. Recuperado de http://remi.revues.org/4245.

Rivera, S. (2010). Violencias (re)encubiertas en Bolivia. La Paz, Bolivia: Editorial Piedra Rota.

Romero, L. (2009). La idea de nación en los libros de texto de historia argentinos del siglo Xx. Publicación del Seminario Internacional Textos Escolares de Historia y Ciencias Sociales. Santiago de Chile: Ministerio de Educación.

Romero, L. (coord.) (2004). La argentina en la escuela. La idea de la nación en los textos escolares. Buenos Aires: Siglo XXI Editores.

Romero-Medina, A. (2010). Educación por y para indígenas y afrocolombianos: las tecnologías de la etnoeducación. Magis. Revista Internacional de Investigación en Educación, 3(5), 167-182.

Sarmiento, D. (1883). Conflicto y armonía de las razas en América. En: Vol. I (1883); Vol. II: póstumo. Vols. XXXVII y XXXVIII de Obras completas. Editorial: Luz del Día (1953). Buenos Aires, Argentina.

Scarzanella, E. (1999). Ni gringos, ni indios. Inmigración, criminalidad y racismo en Argentina 1890-1940. Buenos Aires: Ediciones Universidad Nacional de Quilmes. 
Soler, C. (2008). Pensar la relación análisis crítico del discurso y educación. El caso de la representación de indígenas y afrodescendientes en los manuales escolares de ciencias sociales en Colombia. Discurso \& Sociedad, 2(3), 642-678.

Tedesco, J. (1994). Educación y sociedad en la Argentina (18801900). Buenos Aires, Centro Editor de América Latina.
Uribe, J. (2008). Sociología biológica, eugenesia y biotipología en Colombia y Argentina. (1918-1939)". En: S. Castro y E. Gómez (eds.). Genealogías de la colombianidad (pp. 204-220). Bogotá: Pontificia Universidad Javeriana.

Zárate, A. (2011). Las representaciones sobre los indígenas en los libros de texto de Ciencias Sociales en el Perú. Discurso \& Sociedad, 5(2), 333-375.

\section{Diálogo del conocimiento}

Los puntos sobresalientes del texto "La nación y sus otros" se encuentran en la argumentación de la autora acerca del tema de la escuela como constructora de nación y nacionalidad, lo cual se ha abordado en distintos trabajos, pero no se ha profundizado lo suficiente en lo que respecta a lo que ella llama correlato racista y excluyente. Para ilustrarlo, ella retoma los casos de dos países de América Latina (Colombia y Argentina), en los cuales durante los siglos XVIII y XIX se implementaron políticas homogeneizadoras que no contemplaban tanto a indígenas como a negros dentro de los proyectos de nación, en los que incluso el pasado era negado.

En estos países, tanto indígenas como negros eran pensados como el otro, aquel que no era parte de la nación, ya que se pensaba que eran atrasados, salvajes y que no permitían el progreso de la nación, así que tenían que ser combatidos. Se buscaba avanzar hacia la modernidad, el progreso teniendo como horizonte a Europa, e incluso para lograrlo se apostó a la inmigración para así mejorar la raza, y hacer lo mismo que en países como Uruguay o Chile, donde se intentaba la eliminación de la negritud y de cualquier diferencia.

Para alcanzar sus fines homogeneizadores, las clases dominantes echaron mano de las instituciones políticas, religiosas, pero principalmente de la educativa, ya que esta siempre "ha sido un espacio de transmisión cultural y de socialización de los sujetos y es indudable el papel que ha desempeñado en la formación cultural" (Finocchio, 2012). Esto porque tenían claro que en las escuelas se fomentaba la creación de una identidad única, de una identidad nacional, dentro de la cual solo se consideraban los blancos y mestizos, excluyendo a cualquier diferencia cultural, creando así subalternidades identitarias.

Las escuelas lograban estos objetivos a través de efemérides escolares y de textos escolares, los cuales eran utilizados como herramienta para llevar a cabo políticas desde las cuales se seguía difundiendo el pensamiento de que los avances eran producidos por hombres blancos; de esta manera se fomentaba una lectura eurocéntrica y racista de América Latina, y se reafirmaba un racismo epistémico, ya que aquellos nunca han sido neutrales. A través de tales dispositivos se encuentran a indígenas y a negros representados a través de estereotipos culturales que reafirman el racismo epistémico, con lo cual se prioriza el ideal eurocéntrico y epistemicida de saberes.

Bruno Baronet 